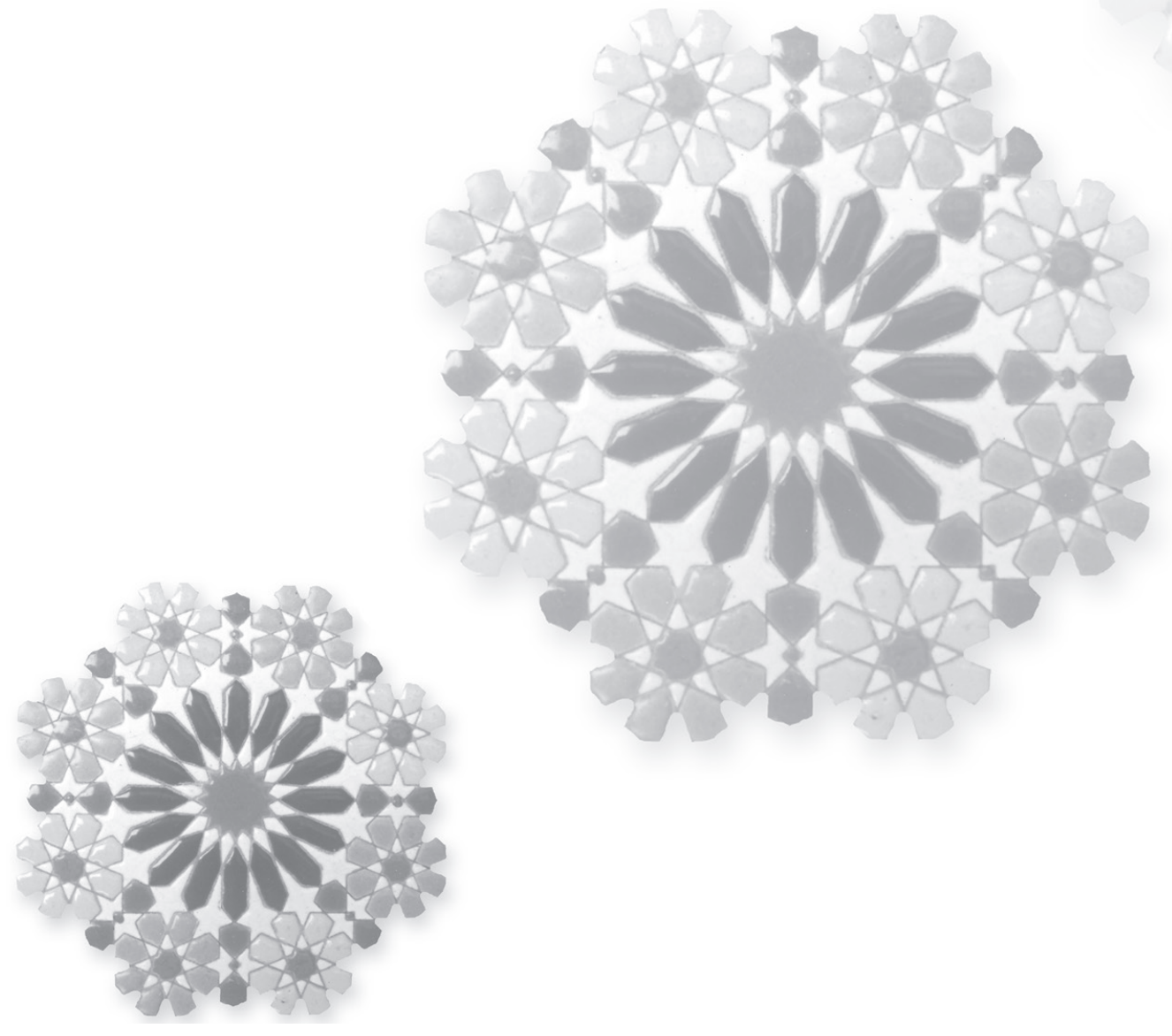




\section{O périplo do exílio de Milton Santos e a formação de sua rede de cooperação}

\section{The long journey of Milton Santos's exile and the formation of his network of cooperation}

Breno Viotto Pedrosa

Professor, Instituto Latino-americano de Tecnologia, Infraestrutura e Território/Universidade Federal da Integração Latino-americana. Foz do Iguaçu - PR - Brasil

breno.pedrosa@unila.edu.br

Recebido em 14 dez. 2016.

Aprovado em 24 ago. 2017
PEDROSA, Breno Viotto. O périplo do exílio de Milton Santos e a formação de sua rede de cooperação. História, Ciências, Saúde - Manguinhos, Rio de Janeiro, v.25, n.2, abr.-jun. 2018, p.429-448.

Resumo

A partir da análise de cartas do acervo de Milton Santos, o artigo revisita seu percurso no exílio, demonstrando sua contribuição para a consolidação da geografia crítica e elementos reveladores da gênese de sua rede intelectual, que envolve pensadores de França, EUA e América Latina. Enfocando os contextos de seu exílio, concatena sua experiência fora do Brasil com novos interesses científicos e a formação de um círculo internacional de cooperação. Secundariamente, evidencia sua preocupação com o planejamento. Constata que sua aproximação com o grupo de Pierre George e François Perroux é seguida por uma crítica que o encaminha para um diálogo com a filosofia marxista e com o estruturalismo.

Palavras-chave: Milton Santos (19262001); rede intelectual; exílio; geografia crítica; planejamento.

\section{Abstract}

Based on an analysis of letters from the Milton Santos collection, the article revisits his journey through exile and shows how he contributed to solidifying the field of critical geography. It also pinpoints elements that reveal the genesis of his intellectual network, which involved thinkers from France, the United States, and Latin America. Focusing on the contexts of his exile, the article links his experiences outside Brazil to new scientific interests and the formation of an international circle of cooperation. Secondarily, it provides evidence of his concern with planning. It is found that his interest in the group of Pierre George and François Perroux was followed by a critical stance that moved him toward dialogue with Marxist philosophy and structuralism.

Keywords: Milton Santos (1926-2001); intellectual network; exile; critical geography; planning. 
C ompreender a trajetória de Milton Santos (1926-2001) é uma tarefa árdua, pois, como todo grande pensador, seu projeto está pautado em princípios que o acompanharam durante seu percurso por contextos sociais complexos. Após um sucinto trabalho no acervo Milton Santos, depositado no Instituto de Estudos Brasileiros (IEB) da Universidade de São Paulo (USP), almejamos contribuir para o entendimento da rede de Milton Santos, que certamente colaborou para sua ida à França no exílio; possivelmente possibilitou sua experiência na Tanzânia e contribuiu para seu papel de interlocutor da geografia crítica, difundindo ideias como editor de periódicos sobre o Terceiro Mundo. Identifica-se um esforço pessoal para compreensão da especificidade do Terceiro Mundo em face das teorias mais propagadas, que têm como referência os países desenvolvidos. Paralelamente, Milton, como editor, divulga as pesquisas e os pesquisadores dos países subdesenvolvidos. Na pesquisa foi examinada a correspondência de Milton Santos, contextualizada com entrevistas, homenagens e outros materiais.

Cabe ressaltar que o acervo de Milton foi depositado mantendo a ordem original dos materiais. O trabalho abordou cartas selecionadas pelo próprio autor, nomeadas, no arquivo, como "relações sociais", destacando que Milton organizou seus materiais por caixas temáticas (Grimm, 2011a).

Não almejamos fazer uma revisão bibliográfica de como Milton está sendo interpretado; entretanto, o grande impacto de sua obra e a plêiade de discípulos e interlocutores geraram um esforço para contar sua trajetória intelectual, seja para enaltecer a figura, seja para compreender seu pensamento. Nesse sentido, para algumas indicações, existem relatos de cunho memorialista (Buss et al., 1991; Souza, 1996; Silva, 2002, Silva, 2011) ${ }^{1}$ ao lado de interpretações predominantemente internalistas (Silva, Silva, 2004; Brito, 2008; Grimm, 2011b; Morais, 2013; Contel, 2014; Melgaço, Prouse, 2017). ${ }^{2}$ Com base no artigo de Jeanpierre (2004), buscamos analisar sua estratégia no exílio. De acordo com os materiais levantados, notamos que Milton se esforçou para manter seus contatos do campo geográfico brasileiro e, ao mesmo tempo, afirmar sua expertise sobre as especificidades do Terceiro Mundo para o público estrangeiro, principalmente no tocante à questão urbana, regional, do planejamento. Seu périplo por várias instituições, onde travou contato com as principais figuras da geografia crítica da França e dos EUA, proporcionou-lhe um acúmulo de capital cultural, com o que promoveu, no seu retorno ao Brasil, uma verdadeira revolução simbólica, uma vez que, na época, a geografia crítica brasileira ganhava força.

Nossos apontamentos buscam suas ligações com a França antes do exílio, quando Santos ocupava uma posição de destaque político e acadêmico na Bahia. Longe de ser exaustiva, a análise elucida a articulação de sua rede francesa e as circunstâncias de seu exílio. Em seu périplo pelo mundo e na ampliação da rede, destaca-se a atuação na revista Antipode junto a Richard Peet, importante figura da geografia radical. Finalmente, na volta ao Brasil, evidenciamos a retomada de relações, a troca epistolar com Neil Smith e alguns projetos editoriais. Durante o exílio, Milton é um viajante compulsivo que participa de eventos, conferências, trabalhos de campo, além de se mudar em busca de trabalho. Neil Smith lembra que, além do posto, herdou de Milton sua ativa caixa de correio, que recebia notícias da geografia de boa parte do mundo. Apesar do novo ocupante, a correspondência 
não parava de chegar, endereçada a Santos, com boletins, informes, periódicos e outras informações (Souza, 1996, p.188).

\section{Milton Santos na Bahia: entre a geografia e a política}

Pouco tem sido dito sobre a origem de Santos, cujos pais, professores, desfrutavam de certo prestígio social. Ele, no entanto, estava exposto às contradições da sociedade baiana, cheia de desigualdades sociais. É provável que tal aspecto reverbere em uma curiosidade geográfica sobre a especificidade de seu lugar e em sua visão otimista dos serviços e do comércio das áreas urbanas e setores pobres nos países subdesenvolvidos, visto por muitos como um obstáculo ao desenvolvimento econômico.

Após a formação inicial proporcionada por seus próprios pais, Santos seguiu para Salvador a fim de continuar seus estudos e, lá, enfrentou o racismo em duas situações marcantes: primeiramente, no impedimento de ingressar na Escola Politécnica, mas, apesar disso, o interesse pela técnica permaneceu. Santos encontrou na geografia francesa uma série de pensadores que refletiram sobre a técnica com um viés geográfico, concepção que sua obra levou às últimas consequências ao afirmar que "a Geografia é a filosofia das técnicas" (Santos, Carvalho, 1965, p.256). ${ }^{3}$ Possivelmente, saltou aos olhos do jovem Milton Santos a necessidade de modernizar a Bahia, onde conviviam a pobreza e a opulência. Santos também enfrentou oposição do Partido Comunista Brasileiro (PCB) à sua candidatura para a União Brasileira de Estudantes Secundaristas (Ubes), o que certamente adiou seu encontro com o marxismo (Mamigonian, 2004, p.134). Contudo, essa não foi sua morte política, visto que, como estudante de direito, conviveu com figuras da União Democrática Nacional (UDN). Não conseguimos aferir o peso do convívio político na formação do pensamento de Santos; contudo, é inegável que tal engajamento resultou em um importante grau de influência e na ocupação de significativos cargos, culminando na subchefia da Casa Civil na Bahia, durante o governo Jânio Quadros. Mais adiante, tal prestígio político se reverte após o golpe de 1964.

Santos não seria apenas um udenista, pois mesmo com sua atuação no jornal $A$ Tarde e a proximidade com seu fundador, Ernesto Simões, pertencente a esse partido, nos parece que seu amadurecimento político e profissional torna sua visão de mundo mais complexa (Machado, 2014). De fato, a UDN fazia oposição a Vargas, defendendo ideias liberais, porém de espectros diversos, sendo que, no Nordeste, o contexto é complexo, em função de seu atraso e da industrialização do Sul. De acordo com Machado (2014, p.153), Santos se aproxima da UDN via movimento regionalista, e seus antigos professores e colegas do direito, como Antônio Lomanto Junior, também eram udenistas. Santos indica que no ambiente profissional de $A$ Tarde existia pluralidade de opiniões, com jornalistas comunistas (Buss et al., 1991, p.128), demonstrando que, mais do que uma orientação liberal, existia um sentimento regionalista e progressista dedicado à Bahia. Prova disso é a eleição de Lomanto, que alia políticos diversos, união que se degrada em 1964.

Em 1956, Santos participa do $28^{\circ}$ Congresso Internacional de Geografia, ${ }^{4}$ no Rio de Janeiro, promovido pela União Geográfica Internacional (UGI). Certamente, o alinhamento de suas análises sobre a Bahia com a metodologia francesa chamou a atenção dos professores 
visitantes, pois, no Brasil, sua obra foi pioneira ao se debruçar sobre as zonas de influência, a rede e a hierarquia urbana (Santos, 1956a, 1956b, 1956c; Silva, Silva, 2004). Apenas na década de 1960 tais concepções seriam aplicadas, pelo Instituto Brasileiro de Geografia e Estatística (IBGE), para o entendimento do território brasileiro.

Na juventude, Santos conheceu a obra de Josué de Castro (Contel, 2014) e, consolidado seu interesse pela geografia, viajava com frequência ao Rio de Janeiro para cursos no IBGE, além de se inteirar sobre a bibliografia estrangeira. Após o evento da UGI, vários professores participaram de atividades nas instituições brasileiras, e dois eventos no Rio chamam atenção: o Curso de Altos Estudos Geográficos organizado por Hilgard Sternberg, um dos mentores do encontro da UGI, de que os geógrafos franceses de esquerda, que eram referência para Santos, foram vetados; e as palestras no Conselho Nacional de Geografia (CNG), organizadas por Pedro Geiger, das quais os franceses participaram em peso. Jean Tricart e Jean Dresch versando sobre geografia física, Pierre George sobre o método da geografia industrial e Michel Rochefort sobre o da geografia urbana (Nogueira, 1956, p.210). O nome de Santos consta da lista do primeiro curso, mas não sabemos se ele vai às palestras no CNG. George relata um trabalho de campo na Bahia, após o encontro da UGI, em que ele visita a zona do cacau (Souza, 1996, p.54), o que mostra a possibilidade de o grupo de geógrafos franceses de esquerda ter visitado Salvador.

Nesse evento, Santos conhece Jean Tricart, que se torna o orientador de seu doutorado sobre o centro de Salvador, além de parceiro, tanto na ampliação de contatos internacionais quanto no subsídio aos temas do planejamento e da geografia urbana. Seu L'habitat urbain, de 1957, redirecionou a geografia urbana brasileira (Mamigonian, 2004, p.127). Em várias ocasiões, Santos afirmou que Tricart o incentivou ao estudo do marxismo, proporcionando uma leitura de segunda mão dessa linha de pensamento (Buss et al., 1991, p.136-137).

Após o doutorado, Santos retorna à Bahia, e, a partir de um convênio de cooperação técnica, é organizado o Laboratório de Geomorfologia e Estudos Regionais na Universidade da Bahia (Ufba). O laboratório, a criação da seção local da Associação de Geógrafos do Brasil (AGB) em Salvador e a fundação do Boletim Baiano de Geografia ocorreriam em 1959 (Contel, 2014, p.395); contudo, ainda antes, em 1958, Tricart viaja ao Brasil, o que resultou na publicação do livro Estudos da geografia da Bahia (Santos et al., 1958). Na "Introdução", Santos afirma que, em 1956, Tricart e Rochefort visitaram a Bahia, o primeiro dirigindo uma série de estudos. O índice da obra revela os temas aos quais Santos se dedica, como a regionalização, as zonas de influência comercial e as redes urbanas e, paralelamente, os trabalhos realizados por Tricart, ou seja, estudos geomorfológicos para o planeajmento. O francês analisa a bacia do Paraguaçu e a barragem do Fertin, refletindo sobre a geração de energia hidroelétrica e as possibilidades de industrialização. Tais preocupações se assemelham à estratégia da Tennessee Valley Authority(TVA), que encara a bacia hidrográfica como unidade de planejamento. ${ }^{5}$

Santos, cada vez mais esclarecido pelo contato com a geografia, após suas experiências no Rio e na França, une as ideias apreendidas ao seu prestígio político para se engajar no planejamento. Nosso autor publica sobre o papel da geografia aplicada, reverberando o debate francês (Santos, Carvalho, 1960, 1965). No exílio, sua preocupação com o planejamento continua. Nessa época, Santos defende que a geografia tenha um papel no 
planejamento regional e territorial, utilizando seus conceitos e categorias para resolver problemas de organização do espaço - por exemplo, a questão das áreas de influência podem detectar as cidades mais e menos desenvolvidas, revelando focos de pobreza. Cabe lembrar que o campo do planejamento regional, em escala mundial, se consolidava de forma difusa no pós-guerra sob efeito do consenso keynesiano. No Brasil, a criação da Companhia do Vale do São Francisco, fruto da cooperação técnica com os EUA, baseada na experiência do TVA, é um exemplo claro da consolidação desse campo. Paralelamente, na década de 1960, o IBGE, sob influência da presença de Michel Rochefort, começa um processo de renovação de temas de pesquisa, preocupando-se com a indústria, o crescimento urbano, as infraestruturas e os serviços e comércio. Como vimos, Santos foi pioneiro na aplicação das ideias de Rochefort para analisar a realidade baiana. Tais preocupações estão em sintonia com o desenvolvimentismo, em voga no Brasil, destacando que a atuação de Santos nos órgãos de planejamento foi influenciada pelo pensamento de Celso Furtado e Rômulo de Almeida.

A vinda de Tricart à Bahia gera um intercâmbio, pois brasileiros, como, por exemplo, Armen Mamigonian e Ana D. Carvalho, vão estudar em Estrasburgo, na sede laboral do geógrafo francês. Mamigonian foi orientado por Étienne Juillard, o que demonstra relações que vão além do elo entre Santos e Tricart. Como sabemos, o IBGE foi um importante nicho de internacionalização da geografia brasileira, e é possível que as relações de Santos consolidem outra fonte, mais restrita, que envolvia geógrafos baianos e seus colegas da AGB.

Milton Santos, como renomada figura, é convidado para chefiar a Imprensa Oficial da Bahia no governo Juraci Magalhães, entre 1959 e 1961. Nosso autor publicou vários estudos geográficos por esse órgão, alguns dos quais republicados em revistas do IBGE (Santos, Carvalho, 1960, 1965).

Em 1962, Santos é presidente da AGB e organiza um evento em Jequié, reduto político de Lomanto Júnior. Na 27a Assembleia da AGB, temos a criação da seção regional baiana e a presença de geógrafos franceses, alguns dos quais participantes do encontro de 1956: Jean Gallais, Anne R. Hirsch, Jacqueline Beaujeu-Garnier, Jean Dresch e Jean Tricart, além de Manuel Correia, Celso Furtado e Caio Prado Jr. Na melhor tradição francesa, Dresch realiza um terrain na Chapada Diamantina (Silva, 2011, p.145-175). O irmão de Santos, Nailton Santos, economista por formação, trabalha na Superintendência do Desenvolvimento do Nordeste (Sudene) ao lado de Celso Furtado, e, provavelmente, essa relação impulsionou seu contato com o planejamento, na Bahia e no exílio. Independentemente do sucesso do evento de Jequié, em 1963, Santos publica nos Annales de Géographie, e é possível, ainda, encontrar dois artigos anteriores, o que demonstra o acúmulo de um capital cultural (Santos, 1959, 1961, 1963).

Pouco antes disso, Santos viaja com Jânio Quadros para Cuba, e, em 1961, ocupa a chefia do gabinete civil. Nesse contexto, com o objetivo de ambientar-se para uma possível nomeação diplomática, viaja em missão à África, onde tem contato com os movimentos de descolonização (Contel, 2014, p.396). No governo de Lomanto, Santos assume a Comissão de Planejamento Econômico da Bahia (CPE), entre 1962 e 1964.

$\mathrm{Na} \mathrm{CPE}$, sua gestão envolve profissionais de esquerda e a influência do planejamento da Sudene - lembremos do papel de Nailton -, com leituras desenvolvimentistas de apelo 
regional. François Perroux influenciou Furtado na Sudene e, certamente, a CPE na Bahia. Coerente com as preocupações de Santos, Joaquim de Oliveira - que foi orientando de Dresch - e Nicole Lacroix estudam a regionalização dos centros urbanos a partir do fluxo de mercadorias, procedimento afim do método Rochefort, que se pauta em ideias de Jacques Boudeville. ${ }^{6}$ Paralelamente, Wolfgang Malrohlz estuda a localização dos recursos minerais, sendo contratado como instrutor na Universidade da Bahia (Silva, 2011, p.176), o que demonstra sinergias entre ela e a CPE.

Fernando Pedrão (Souza, 1996, p.59-60) acrescenta que a figura de Santos no planejamento, de um lado, representou a diretriz política de Jânio Quadros nos estados e, de outro, se ligou ao municipalismo, proposta que beneficiava os municípios. Tal engajamento provoca sua aceitação pela classe média urbana, porém, sua atuação foi além do municipalismo - entre 1953 e 1964 ele publica vários artigos na Revista Brasileira dos Municípios -, pois rompe com favorecimentos pontuais para pensar o espaço regional globalmente, beneficiando a indústria e o setor petrolífero. Ainda segundo Fernando Pedrão, a CPE se inspirava no economista Rômulo de Almeida.

De acordo com Machado (2014, p.156), além de a CPE abrigar pessoas vinculadas ao partido comunista, Santos se encontrava com certa frequência, no Rio de Janeiro, com Guerreiro Ramos e Josué de Castro, ambos, na época, deputados pelo Partido Trabalhista Brasileiro (PTB), sendo que Ramos e Cândido Mendes eram apoiadores de João Goulart (Contel, 2014, p.396). Paralelamente, a viagem de Santos a Cuba lhe rendeu um registro nos aparelhos de repressão. Jânio fora eleito em um contexto em que sua figura representava uma visão liberal-democrata que, na realidade, escamoteava uma série de posições políticas discrepantes (Souza, 1996, p.59), e a frente que elegeu Lomanto sofria do mesmo mal. Lomanto tolera a CPE, mas apoia o golpe de 1964 e entrega Santos como um bode expiatório que demarca sua posição diante do novo governo, expurgando um órgão associado à esquerda e ao planejamento, contrário aos interesses das elites latifundiárias que imaginavam a modernização como um fator desestabilizador das formas de dominação social. Com a ajuda dos contatos na área da geografia, Santos vai lecionar na França, mesmo país em que seu irmão se exila, por meio de outras redes intelectuais (Machado, 2014, p.156-157).

Ao sair do Brasil, além dos cargos políticos que ocupava, Santos era livre-docente em geografia humana na Universidade da Bahia. Em 1964, após ter ocorrido em Jequié, a reunião da AGB teve lugar em Poços de Caldas, nela Armen Mamigonian dedicou sua apresentação a Santos, que estava preso (Silva, 2011, p.71).

\section{Da Bahia para o mundo: entre o terceiro-mundismo e o marxismo}

Agora nos debruçaremos sobre o exílio de Santos, que vai de 1964 a 1977, período a respeito do qual existem poucas informações, se comparado à trajetória baiana ou após o retorno ao Brasil. Isso se deve ao périplo que envolveu vários lugares e até certa medida não foi planejado, pois dependeu de convites ou inscrições, de trabalhos quase sempre temporários, implicando, provavelmente, instabilidade que contrasta com o convívio intenso com grupos de geografia da França e dos EUA. 
Inicialmente, após a ação dos colegas franceses, Santos leciona na Universidade de Toulouse. Aí permanece entre 1964 e 1967 e, em contato com Bernard Kayser, desenvolve atividades no Institut d'Étude du Développement Économique et Social (Iedes), que, sob liderança de François Perroux, agrega membros que se dedicam à economia do desenvolvimento, utilizando algumas inspirações keynesianas e onde se observa um forte interesse pelo Terceiro Mundo. Ligada ao instituto, surge a revista Tiers Monde, focalizando os países subdesenvolvidos, da qual Santos é assíduo colaborador. Nesse período, a aproximação entre Santos e Kayser possivelmente foi impulsionada pelo viés terceiro-mundista do último, preocupado em apreender a especificidade do subdesenvolvimento, assim como de seu mestre, Pierre George, e seus colegas, dentre os quais é possível destacar Yves Lacoste e Michel Rochefort.

Nos primeiros anos de exílio, Santos demonstra insatisfação com a geografia francesa, uma vez que ela não explica as especificidades do Terceiro Mundo (Buss et al., 1991, p.138). A longo prazo, o resultado do esforço de teorização que se avoluma é o livro Espaço dividido (1975, primeira edição em francês). Em Toulouse, Santos ministra um curso sobre a fome nas cidades subdesenvolvidas, recuperando um tema afim de Josué de Castro, o que resulta na publicação de seu primeiro artigo na Tiers Monde (Santos, 1967).

Chama nossa atenção sua opção de não perder contato com colegas brasileiros. Nota-se um fluxo de cartas entre Santos e José Ribeiro de Araújo Filho, professor da Universidade de São Paulo, ${ }^{7}$ uma amizade advinda da atuação de ambos na AGB. Na carta destinada a Araújo, de 1966, Santos (Silva, 2011, p.330) conta que Lysia Bernardes havia lhe escrito para informar sua nomeação como chefe da Divisão de Geografia do IBGE. Santos também se corresponde com outros brasileiros, e, possivelmente, seu acervo revelará mais trocas epistolares. Jeanpierre (2004) demonstrou as várias estratégias dos antropólogos no exílio, e, possivelmente, Santos ampliou sua rede internacional sem deixar de manter contatos brasileiros, informando-se sobre os principais atores e instituições, provavelmente, na perspectiva de retornar ao Brasil. $\mathrm{O}$ autor diferencia distintas estratégias dos intelectuais no exílio, uns mais preocupados em acumular capital cultural nas novas terras e outros em manter o prestígio junto aos pares da terra natal. Notamos que Milton tenta, na medida do possível, sustentar ambas ao se corresponder com os colegas da geografia brasileira, alguns deles já ocupando cargos importantes nas diversas instituições, e, ao mesmo tempo, colocando-se para os pares do campo na França e nos EUA como detentor de um conhecimento que lhe confere distinção: a realidade dos países subdesenvolvidos.

O contato com o Iedes e com Perroux proporcionou condições para o aprofundamento do tema do planejamento, da economia espacial, da difusão de inovações e das definições de desenvolvimento e subdesenvolvimento. Tais temas se relacionam com o corpo teórico elaborado inicialmente por Perroux, cuja delimitação não é simples. Perroux cria uma teoria do desenvolvimento, demarca o conceito de espaço econômico, escreve sobre a questão do valor, dialoga com a ciência regional de Walter Isard, além de incorporar ideias de geógrafos como Jean Gottman. Em contato com esse arcabouço, Santos, com Dresch, Tricart, John Peter Cole e Rochefort, participa, em 1966, do encontro regional da UGI no México, cujo mote é a aplicação da geografia, em que se abordam temas como o uso do 
solo e o subdesenvolvimento (Bomfim, Vargas, 2014). A conferência remonta ao debate controverso da geografia aplicada ou da geografia ativa.

Entre 1967 e 1968, Santos trabalha na Universidade de Bordeaux, onde ocorre, em 1968, o seminário internacional "La régionalisation de l'espace au Brésil", realizado pelo Centro de Estudos de Geografia Tropical. O evento reúne grandes nomes da geografia francesa e brasileira: Louis Papy, Pierre Monbeig e Pierre Deffontaines, que haviam trabalhado ou ministrado cursos no Brasil, além de Etienne Juillard e Bernard Kayser. Pierre George (1970) mostra uma análise da área urbana de São Paulo, lembrando que, em 1968, ele dá palestras e realiza trabalho de campo no Brasil. Michel Rochefort palestra sobre a cidade e a organização do espaço no Brasil após sua atuação no IBGE. Santos apresenta um comentário que traça a história recente do Nordeste, com destaque para a urbanização e a industrialização, e estudo sobre agricultura e regionalização. Manoel C. de Andrade, Pedro Geiger e Lysia Bernardes também participam do evento, o primeiro com um trabalho sobre espaços homogêneos em Pernambuco, e os outros dois com os resultados de suas pesquisas, com a metodologia de Rochefort, sobre a hierarquia urbana, a rede de cidades e a industrialização, proposta que se articula com as concepções de espaços homogêneos e polarizados como disposto por Jacques Boudeville, discípulo de Perroux e membro do Iedes (Centre..., 1971).

Entre 1968 e 1971, Santos trabalha na Sorbonne e no Iedes, em Paris, sendo considerado por seu conhecimento sobre o Terceiro Mundo. De acordo com Grimm (2011a, p.175-176), um dos impulsos para tal julgamento é a publicação no Brasil, em 1965, e na França, em 1971, do livro As cidades nos países subdesenvolvidos. Ainda em 1971, Santos publica em francês o livro O trabalho do geógrafo no Terceiro Mundo, criticando o empirismo da geografia francesa. Nele, propõe a procura de abstrações teóricas para apreensão do espaço, além de atentar para as especificidades do subdesenvolvimento. Nesse momento, temos a busca de uma geografia própria, para além da reprodução dos modos de fazer precedentes, sem deixar de reconhecer o papel dos mestres nem poupá-los de crítica.

Na Sorbonne, Santos colabora sistematicamente com a revista Tiers Monde, ${ }^{8}$ que trata essencialmente do desenvolvimento nos países do Terceiro Mundo e sua interface com a agricultura, o urbanismo, a educação, a economia, as relações internacionais, para citar alguns temas. Em 1971, ele organiza um número especial que reúne artigos sobre "a organização do espaço nos países em desenvolvimento", oferendo uma amostra de seu capital cultural como especialista. Do sumário da revista constam importantes autores do planejamento regional, entre os quais, John Friedmann. José Ramón Lasuén publica no número, assim como Terence (Terry) McGee e Llyod Rodwin, sendo que o último convida Santos para atuar no Massachusetts Institute of Technology (MIT), nos EUA (Contel, 2014, p.387). Paralelamente, McGee se torna seu parceiro de trabalho.

O número revela uma preocupação em cobrir América Latina, África e Ásia, abordando o planejamento, a geografia urbana e da indústria, incluindo a teoria dos polos. Nesse período, destaca-se ainda o apoio de Santos a Jacques Lévy, auxiliando-o na consolidação do grupo em torno da revista Espace-Temps, originariamente de orientação althusseriana (Pedrosa, 2013, p.232). 
De acordo com Grimm (2011a, p.176), Santos, na França, aprofunda seu contato com a filosofia; concomitantemente, em pleno maio de 1968, ele estaria provavelmente em Paris. O movimento de 1968 foi antecedido por ampla divulgação do pensamento de Althusser, sendo o marxismo estruturalista debatido por parte da esquerda, e, como demonstra Cusset (2005), a filosofia francesa é bem recebida no ambiente intelectual estadunidense. Nossa hipótese é a de que Santos, nos seus anos na França, tenha estudado tanto a filosofia de Sartre quanto a de Althusser; contudo, somente a análise documental pode confirmar isso. Ao participar do grupo de geógrafos radicais estadunidenses, seu texto sobre a formação socioespacial, de 1977, tem inspiração althusseriana, sendo que, devido ao acesso às bibliotecas, o período na França deve ser visto como um aprofundamento em várias temáticas, entre elas a filosofia. Possivelmente, Santos leva para os EUA a novidade francesa; entretanto, novamente em terras americanas, ele se dedica ao estudo sistemático do marxismo, o que leva a supor um eventual aprofundamento no estruturalismo marxista (Buss et al., 1991, p.140).

Em 1972, Santos vai para o Programa Especial para Estudos Urbanos e Regionais (SPURS) no MIT, em Cambrigde. O SPURS se dedica ao estudo de países subdesenvolvidos, articulando planejamento, economia, urbanismo, arquitetura e geografia, envolvendo pesquisadores estrangeiros.

O período no MIT representa a radicalização de algumas posturas. Santos, que estava entre "o populismo e a esquerda" (Buss et al., 1991, p.136), vê nos EUA a produção de uma ciência para a guerra, em um ambiente de competitividade acadêmica no qual se contrapõem os nacionalistas e os críticos à guerra do Vietnã, provocando uma retomada do marxismo.

Em 1972 e 1973, Santos trabalha na Universidade de Toronto, onde esperava conviver com Florestan Fernandes. Não conseguimos precisar se isso ocorreu, uma vez que em 1973 Florestan retorna ao Brasil. Segundo Contel (2014, p.398), é no Canadá que Santos finaliza a redação de Espaço dividido (1979).

Contatos com a Organização dos Estados Americanos (OEA) permitem que Santos vá, em 1973, trabalhar três meses na Universidad Nacional de Ingeniería, em Lima, envolvendose com brasileiros que atuam na Organização Internacional do Trabalho (OIT). Essa entidade demanda uma pesquisa sobre a pobreza nas cidades da América Latina, que não foi publicada (Buss et al., 1991, p.138-139). Seu irmão Nailton também esteve envolvido com a OIT, atuando no órgão entre 1965 e 1966 (Silva, 2011, p.178). A experiência da OIT permitiu a visita a países como Costa do Marfim, Daomé, Gana, Togo, Tunísia, Argélia, Cuba, México e Colômbia (Contel, 2014, p.399), e, em 1975, Santos está no Centro de Estudios del Desarollo da Universidad Central de Venezuela, em contato com o economista Domingo Maza Zavala. Nesse mesmo ano, devido ao contato com a OEA, Santos ministra cursos na Costa Rica (Silva, 2011, p.262).

Segundo relato (Buss et al., 1991, p.138), no início da década de 1970, Santos é convidado por Ruth Glass para integrar o Centre for Urban Studies, da University College London (UCL), convite que declina ao não receber apoio para seu estabelecimento em Londres. Glass é uma eminente socióloga, que estudou a gentrificação, planificação e migração das populações do Terceiro Mundo em Londres. 
Entre 1974 e 1976, Santos vai para Universidade de Dar es-Salaam, na Tanzânia, episódio sobre o qual não há muitas informações. Segundo Buss et al. (1991, p.139), Santos vai a Tanzânia para organizar um programa de pós-graduação em geografia e lá é nomeado membro do comitê diretor do programa de Emprego e de Urbanização da OIT. Em função da revolução socialista na Tanzânia, a universidade reuniu um grupo de marxistas, como o geógrafo David Slater. Após sua experiência, Santos escreve um artigo, pouco discutido, em que compartilha sua leitura sobre o país e problematiza as consequências da modernização no campo e a centralização excessiva de Dar es-Salaam, defendendo a mudança da capital do país e a necessidade de um planejamento não capitalista que fosse coerente com a formação socioespacial da Tanzânia (Santos, 1978). Destacamos que Santos afirma ter aprofundado, nesse período, os estudos sobre filosofia e física, com uma provável aproximação da nova geografia, pois tal influência aparece em Por uma geografia nova (1978).

Em decorrência do esforço teórico e empírico sobre as cidades do Terceiro Mundo, Santos publica em 1975, em francês, O espaço dividido, expondo a teoria dos dois circuitos da economia urbana nos países subdesenvolvidos - em inglês, a obra é lançada em 1979. No mesmo ano, Santos se candidata à vaga de professor na Bahia, mas não é bem-sucedido (Buss et al., 1991, p.141).

Entre 1976 e 1977, Santos atua na Universidade de Columbia, em Nova York, de onde seguiria para Nigéria, a fim de auxiliar na criação de uma universidade no Biafra, mas decide voltar ao Brasil. Em 1976, convidado por Maria de Azevedo Brandão para o encontro da Sociedade Brasileira para o Progresso da Ciência (SBPC), Santos esteve no Brasil e se encontrou com antigos contatos, como Armen Mamigonian, que cogita sua ida para a Universidade Estadual Paulista (Unesp) de Presidente Prudente, porém o processo foi negado pela reitoria (Silva, 2011, p.68; Contel, 2014, p.399). Silva (2011, p.334) mostra uma carta de Santos para Mamigonian em que fica clara a expectativa de ingresso na universidade. Segundo entrevista, Pierre George, que mantinha contato com geógrafos brasileiros atuantes no Instituto Panamericano de Geografia e História (IPGH) - entidade que era dominada por geógrafos do IBGE -, avisou que não seria fácil Santos retornar ao Brasil (Buss et al., 1991).

Contudo, antes do retorno, em Nova York, surge o contato com figuras da geografia radical, ${ }^{9}$ como William Bunge e, principalmente, Richard Peet (Contel, 2014, p.399). Peet trabalha com Santos a distância na edição do número da Antipode sobre subdesenvolvimento. Estavam planejados três números temáticos, mas apenas dois foram publicados. Santos, além de assinar com Peet o editorial do primeiro número, foi um importante articulador, recebendo materiais de intelectuais do Terceiro Mundo ainda quando estava provavelmente na Tanzânia, e, nesse sentido, não conseguimos saber exatamente em que ocasião Santos conhece Peet, ou mesmo se David Slater teve algum papel nesse processo.

Na missiva de junho de 1976, o professor Vernon Chandra Mulchansingh (11 jun. 1976), da Universidade das Índias Ocidentais (cuja sede fica na Jamaica e congrega países do Caribe), oferece um artigo para Antipode intitulado "Aspectos espaciais da dependência: um prolegômeno ao planejamento total", ${ }^{10}$ advertindo que uma versão resumida seria publicada na seção 6 do congresso da UGI de 1976. A carta de Akinsola Akiwowo (27 set. 1976) solicita a Santos uma cópia do número especial da Antipode que seria publicado. 
Santos se corresponde ainda com Javier Lindenboim (16 jul. 1976), argentino, da Sociedad Interamericana de Planificación, enviando materiais da Antipode que poderiam ser republicados pela Sociedad, mediante autorização. Portanto, além de receber materiais, Santos articulava também sua divulgação na América Latina.

Além disso, a carta de Uyanga (dez. 1976), da Universidade de Calabar, na Nigéria, propõe o artigo "Perspectivas sobre o crescimento nacional e desenvolvimento regional na Nigéria, 1960-70". ${ }^{11}$ Junto à carta, temos uma anotação, provavelmente de Peet, perguntando se Santos gostaria de incluí-lo na revista.

Cabe destacar que o subdesenvolvimento é bastante debatido na Antipode, aparecendo de forma diluída nas décadas de 1960 e 1970. Contudo, no volume 9, número 1, de 1977, organizado por Santos e Peet, existe uma quantidade maior de artigos de pensadores do Terceiro Mundo do que da geografia anglo-saxônica.

O primeiro número especial da Antipode se inicia com o hoje clássico "Sociedade e espaço: a formação social como teoria e método" (Santos, 1977). Como mencionado, é difícil precisar quanto Santos entra em contato com o estruturalismo; contudo, o período de retorno da África e a nova estada nos EUA são marcados por um engajamento na geografia radical. Do ponto de vista teórico, a formação social determina uma influência do estruturalismo marxista, sendo que, como pontuou Contel (2014, p.403), Santos absorve a ideia de espaço como instância social e operacionaliza a categoria de totalidade. Aqui recomeçam as controvérsias, pois é difícil esclarecer qual obra, se a de Althusser ou a de Sartre, teve maior peso na sua concepção de totalidade.

Nota-se ainda que uma revisão crítica é dedicada ao planejamento e às concepções de Perroux e companhia. Longe do niilismo, Santos expõe as contradições do planejamento que atende às empresas, ignorando os pobres e as heranças do local. O resultado é o desarranjo dos lugares e modernizações que servem ao capitalismo, aumentando as desigualdades e os problemas locais. Paralelamente, nos EUA, Santos participa de encontros da Associação Americana de Geógrafos (AAG), questionando a "geografia tradicional", e, ao se despedir, Peet o presenteia com o livro de Sartre Questão de método (Souza, 1996, p.168).

Retomando o número da Antipode organizado por Santos e Peet, temos o texto "Formas sociais da organização espacial e seus aspectos na América Latina", de José Coraggio, que trabalhava no El Colegio de México. Coraggio é um dos intelectuais críticos à teoria dos polos de desenvolvimento. Temos ainda "Geopolíticas e movimentos nacionais: um ensaio sobre a dialética do imperialismo", de Anouar Abdel-Malek, ligado ao CNRS (Paris); "Prática política e espaço", de Sonia Barros, da Universidade Central da Venezuela; "Economia política e transporte rural: uma reavaliação dos impactos do transporte", de Michael Keith McCall, da Universidade de Dar es-Salaam; "Produção agrícola camponesa no leste da África: a natureza e as consequências da dependência", por Bashir A. Datoo, também da Universidade de Dar es-Salaam; "Produção primária, exportação da produção e distribuição do lucro em uma região atrasada", por Alejandro Forman e Ruiz Alberto Romero, do Instituto Torcuato Di Tella de Buenos Aires; "Esquemas para o estudo de regiões: o caso do México", por Angel B. Batalla, da Universidade Autônoma do México; "População e recursos naturais: limites estruturais e o paradoxo da tecnologia", por Domingo Maza Zavala, da Universidade Central da Venezuela; e, por fim, "Comércio externo e organização 
social: uma tipologia", por George Coutsinas e Catherine Paix, do Iedes, o que demonstra o contato com esse núcleo, apesar das críticas.

Encontramos um conjunto de cartas, que abrange os anos de 1977 e 1978 e que se inicia com a missiva de Santos (mar. 1977), em que ele informa que foram feitas novas assinaturas da Antipode e pede mais exemplares, sugerindo que os autores recebam vinte exemplares para revenda. Em outubro, Peet (out. 1977) informa que enviou cinco cópias da Antipode organizada com Santos para Coraggio, vinte para Zavala e que recomeçará o trabalho para os demais números sobre o subdesenvolvimento. Peet relata que está insatisfeito na Universidade de Clark e que pensa em trabalhar na Austrália - ironicamente, Peet desenvolve toda sua carreira em Clark. Ele conta ainda que publicou o livro Radical geography (1977), ${ }_{12}^{12}$ uma coletânea que reúne contribuições de vários autores que se alinhavam com a geografia crítica e com o marxismo. Ela contém textos de Yves Lacoste, Henri Lefebvre, excertos de Élisée Reclus e Piotr Kropotkin, além de contribuições de figuras eminentes da geografia radical, como o próprio Peet, Doreen Massey, William Bunge, David Harvey, David Slater, James Morris Blaut e Keith Buchanan. Os temas são: (1) humanos, natureza e natureza humana; (2) a geografia histórica do capitalismo; (3) desigualdade e pobreza; (4) grupos minoritários; (5) habitação e luta de classes; (6) teoria da localização; (7) geografia comportamental; (8) ambiente, recursos e povo; (9) a geografia da guerra; (10) imperialismo e geopolítica; (11) subdesenvolvimento; (12) planejamento espacial; e (13) modos alternativos de desenvolvimento. Vemos um contato entre a geografia francesa e a estadunidense, porém, não é coincidência o livro ser publicado no mesmo ano em que um número da Antipode congrega autores do Terceiro Mundo. Aparentemente, temos uma estratégia de projeção da geografia radical em âmbito mundial, ampliando o diálogo entre aqueles que se alinham com uma agenda comum - em que o subdesenvolvimento ganha relevo especial - e uma aproximação com o marxismo.

O número 2, volume 9, da Antipode continua a estratégia de articular geógrafos críticos do mundo e figuras em ascensão da geografia anglo-saxã, como Neil Smith e William Bunge. Em dezembro de 1977, o número seguinte da Antipode é o segundo e último da série sobre o subdesenvolvimento. Milton Santos contribui com "Dialética espacial: os dois circuitos da economia urbana nos países subdesenvolvidos"13 e "Planejamento ou subdesenvolvimento". Ressaltamos ainda a publicação de "Emprego urbano: o caso da Bahia", de Inaia M.M. de Carvalho, da Universidade da Bahia, e o texto de Yves Lacoste "Reflexões autocríticas e crítica da 'geografia do subdesenvolvimento'”, uma revisão de sua célebre obra.

Retomando o fluxo das cartas, Peet (dez. 1977) discute com Santos a permissão para a publicação de artigos e relembra que existiriam ainda, em dezembro de 1977, dois números sobre subdesenvolvimento, contudo, se queixa da má qualidade de muitos artigos, cuja densidade não se compara com o que foi publicado antes. Ele se oferece para escrever aos autores que tiveram os textos recusados, afirmando que usaria um ou dois textos dos recebidos na chamada pública. Peet se queixa da falta de dinheiro para os novos números da Antipode e diz que vai para a Austrália por dois anos estudar o subdesenvolvimento.

Ainda em dezembro de 1977, Peet (dez. 1977) escreve após a edição dos artigos remanescentes e, no último número da série, trabalha com Philip O’Keefe, geógrafo 
engajado na geografia crítica, editor da Antipode e figura dedicada à questão ambiental. Ambos escrevem uma introdução para o volume, e, como dissemos, Santos tem dois artigos aprovados. Peet reporta quais foram os autores aprovados - ao compararmos a carta com o sumário do v.9, n.3, 1977, há uma correspondência completa. Peet pergunta as filiações acadêmicas de German Wettstein, Yves Lacoste, Inaia M.M. Carvalho e do próprio Santos - sendo registrado laconicamente apenas "São Paulo, Brazil", pois na época, possivelmente, ele estava ligado a um órgão de planejamento, mas não à universidade. Isso nos mostra que, apesar das dificuldades de comunicação internacional inerentes à época, Santos teve um importante papel, usando sua rede de contatos na África, na América Latina e na França para reunir materiais, informações e pesquisadores que trabalham sobre temas afins aos de suas pesquisas, notadamente aspectos urbanos, regionais e do planejamento no mundo subdesenvolvido. Finalmente, Peet pergunta se Santos gostaria de escrever uma introdução ao número, convite que declina. Anexo à missiva, Peet envia o livro Radical geography e o artigo "The development of radical geography in the United States".

Na última carta da série, de fevereiro de 1978, Santos (fev. 1978), já no Brasil, escreve a Peet solicitando autorização para publicar seus textos em uma coletânea (reader no original) que compreenderia artigos da geografia crítica entre 1975 e 1980. Santos não menciona os títulos dos artigos, mas informa que foram publicados no Progress in Human Geography; provavelmente refere-se ao mencionado "The development..." (Peet, 1977), cuja versão francesa lhe fora oferecida por Lacoste, e outro texto sobre pobreza publicado nos anais da AAG. ${ }^{14} \mathrm{O}$ pedido teria sido feito por um editor brasileiro, e Santos pretende que o livro seja lançado antes de julho de 1978, mês em que ocorreria o congresso da AGB em Fortaleza. Santos tinha clareza da importância da geografia crítica, que ganhava força no Brasil, e, certamente, se preparava para o evento que transformaria a AGB. Sobre as recusas dos textos submetidos à Antipode, Santos afirma que estava em contato com os autores desde 1974 e que eles esperam a publicação de seus artigos. Diz ainda que não sabe os critérios de seleção, que não se sente confortável em avisar sobre as recusas e que não recebeu o ensaio introdutório do número, sendo difícil assiná-lo ou fazer nova proposta diante dos acontecimentos. Santos se queixa de um baixo número de intelectuais do Terceiro Mundo no último número da Antipode.

Nota-se então o processo capitaneado por Peet para transformar a Antipode em uma publicação academicamente respeitável, ao contrário do que ocorreu nos primeiros números, em que a militância política pesava mais do que os critérios científicos. Santos continua a trocar cartas com Peet (3 fev. 1983), discutindo o envio de novos exemplares da Antipode, assinaturas e envio de remessas.

Santos retorna ao Brasil em 1977, não sabemos ao certo o mês, para que seu filho nasça na Bahia. Ele não reouve o posto na Universidade da Bahia e, por intermédio de Maria Adélia A. de Souza, vai a São Paulo atuar no planejamento (Buss et al., 1991, p.142) que provocou seu exílio e agora lhe oferta um novo início em terras brasileiras. Logo após, Santos vai trabalhar na Universidade de Federal do Rio de Janeiro (UFRJ), entre 1979 e 1983. 


\section{Considerações finais}

Novamente no Brasil, o fluxo epistolar de Santos continua intenso. No seu acervo é possível encontrar uma caixa com correspondências de 1982 a 1985, e, como dissemos, ao retornar ele reforça antigos contatos brasileiros e dá continuidade ao diálogo com os estrangeiros.

A experiência de Santos no exterior provocou uma revolução simbólica nos termos colocados por Jeanpierre (2004), ou seja, ele acumulou capital cultural e chegou no Brasil no momento de ascensão da geografia crítica. Mesmo sem vínculo institucional com uma universidade, vemos que ele se preparou para o encontro da AGB de 1978, pronto para catalizar a geografia crítica. Santos não se colocou em posição de vítima ou herói, primando pelo valor de suas ideias. Certamente a revolução simbólica teve dois lados, o receio de alguns, ligados ou não à geografia crítica, e o seu enaltecimento profissional em face de sua trajetória, seus contatos e publicações.

Paralelamente, o retorno ao Brasil é acompanhado por algumas cartas dos geógrafos franceses, como a de Jacqueline Beaujeu-Garnier (9 jan. 1978), que, em tom íntimo, faz votos para que Santos se restabeleça na Bahia.

No mesmo espírito da missiva dirigida a Peet, Santos (6 mar. 1978) escreve para David Slater, que estava na Universidade de Amsterdã. Milton Santos, que se encontrava em São Paulo, diz que a adaptação à cidade é dura e pede autorização para publicar "A pobreza da investigação geográfica moderna", ${ }^{15}$ na coletânea já mencionada. Santos acrescenta: "Isto é para introduzir um novo impulso na nossa disciplina que está conhecendo agora uma espécie de renovação"; ${ }^{16}$ temos aí mais uma evidência do seu preparo para o evento da AGB.

Outro documento interessante é a carta em que Roberto Lobato Corrêa (3 mar. 1978) envia cópia do artigo sobre o conceito de espaço para a mesa-redonda do encontro da AGB. Ele pergunta se as obras Espaço dividido e Por uma geografia nova estavam disponíveis em português. Alguns dias depois ele envia nova carta com os trabalhos de Armen Mamigonian, Olga B. de Lima e Maurício de Abreu, que participariam, em Fortaleza, da mesma sessão sobre geografia urbana. O evento seria aberto ao público, e o debate ocorreria apenas entre os membros da mesa. Lobato e Armen já haviam discutido publicamente no encontro anterior, em 1976, contrapondo visões distintas, uma baseada na nova geografia, outra, no marxismo. É nessa sessão em Fortaleza que o debate eclode e dá início ao processo político que transforma a AGB, democratizando o acesso a novos membros.

Além do debate no terceiro Encontro Nacional de Geógrafos, lembramos que são publicados em português os seus livros Por uma geografia nova e O trabalho do geógrafo no Terceiro Mundo, em 1978, que, unidos a outras contribuições de geógrafos marxistas, fazem ganhar força a geografia crítica brasileira (Grimm, 2011a, p.177).

Além disso, as cartas revelam o diálogo entre Santos e Neil Smith (21 jun. 1978). As missivas se iniciam em junho de 1976, com Neil, estudante de pós-graduação na Universidade Johns Hopkins, orientando de David Harvey, e Santos ainda no exílio (Smith, jun. 1976). Neil responde a Santos sobre um pedido de cópias que não fica claro nas missivas. De qualquer forma, Smith pergunta se Santos contribuiria em um projeto 
da União Socialista de Geógrafos (USG), cujo título era "Desenvolvimento desigual e meio ambiente". ${ }^{17} \mathrm{O}$ objetivo é compor um livro antítese da geografia ortodoxa, ou seja, uma busca de modelos alternativos. Para Neil, o livro deve ser um "anti-Haggett", fazendo alusão ao clássico Anti-Dühring de Engels e lembrando Peter Haggett, um dos principais nomes da geografia quantitativa. ${ }^{18}$ Smith envia uma cópia da estrutura do livro, que estaria dividido em quatro partes: (I) Materialismo e geografia: (a) materialismo histórico, (b) geografia como ideologia e tecnologia, (c) definições: desenvolvimento, meio ambiente, localização; (II) Desenvolvimento desigual: (a) crítica aos modelos de desenvolvimento, (b) imperialismo, (c) subdesenvolvimento regional, (d) capital urbano e padrões espaciais; (III) Meio ambiente: (a) crítica dos modelos ecológicos, determinismo, (b) recursos como commodities, (c) população e classe, (d) riscos, (e) cultura e percepção; e (IV) Geografia e socialismo: (a) socialismo e meio ambiente.

Inicialmente, o livro de caráter didático seria publicado pela Antipode, mas a editora Methuen - a mesma que publicou o livro de Peet - oferece um contrato. Neil Smith e O'Keefe eram os coordenadores locais de Clark. Neil, preocupado em construir uma obra coletiva sintética, relata a forma de funcionamento da USG, pois, para o livro, cada uma das seções locais enviaria contribuições de 25 a 30 páginas até outubro de 1978, e aqueles que se comprometessem a escrever deveriam se manifestar até agosto, lembrando que o projeto estava aberto a sugestões.

Na carta de Smith (7 set. 1978) fica claro que Santos mostra interesse em contribuir para o livro, e o geógrafo explica que os prazos foram estendidos e o projeto como um todo foi reelaborado a partir das críticas feitas no encontro da USG em Toronto. A orientação é para que se façam textos gerais e didáticos, sendo Santos indicado para escrever sobre o desenvolvimento desigual em escala urbana. Smith comenta que, para o capítulo 3, "Conceitos: desenvolvimento, meio ambiente e localização", ${ }^{19}$ se esperam poucos textos e pede para que Santos opte pela contribuição que lhe for mais conveniente. Smith pergunta como vai o projeto de Santos "o espaço do homem", que, possivelmente, resulta no livro Pensando o espaço do homem, de 1982. Ele menciona que está escrevendo sobre gentrificação, que pretende submeter o texto à Antipode no próximo ano e lhe envia uma cópia. Ele havia passado 1974 e 1975 como intercambista na Universidade da Pennsylvania, onde se deparou com Society Hill, uma das primeiras gentrificações dos EUA. Smith (fev. 1978) envia o esboço de "Gentrificação e capital: prática e ideologia em Society Hill", publicado posteriormente pela Antipode (Smith, 1979). Notando a importância da renda diferencial como elemento da dinâmica urbana capitalista, se dedica, na Universidade Johns Hopkins, a pensar uma teoria da gentrificação (Mitchell, 2014, p.216-217).

Nas cartas trocadas transparece o interesse de Smith sobre o tema da natureza e do desenvolvimento desigual, assuntos analisados na sua dissertação defendida em 1982. De acordo com Mitchell (2014, p.217), Smith criticou a teoria marxista da natureza de Alfred Schmidt, evidenciando a dualidade que envolve esse conceito, pois a natureza é externa aos humanos e universal ao capitalismo, sendo desigualmente produzida, apropriada e transformada pelo homem. Após a defesa, sua dissertação foi rapidamente publicada e, a seguir, Smith ocupa na Universidade de Columbia o posto que fora de Santos (p.217). 
Em fevereiro, Santos (29 fev. 1980) escreve uma carta para Yves Lacoste pedindo providências sobre uma entrevista "desastrosa" publicada na "Hérodote n.57 [sic]". Pelo contexto da carta, Lacoste publicou o rascunho sem alterações, e Santos pede sua republicação, algo que cremos não ter ocorrido.

Em março de 1980, Santos recebe uma carta de Aziz Ab’Sáber (30 mar. 1980) cujo teor interessará a quem quiser reconstruir a história do Departamento de Geografia da USP. Aziz comenta, provavelmente, o processo de saída de Armen da Unesp de Presidente Prudente e a reprovação de Armando C. da Silva na tentativa de se incorporar à Geografia da USP. Aziz faz votos de que Santos se candidate e assuma uma das vagas de professor titular, pois Dirceu Lino de Mattos e Antônio Rocha Penteado iriam se aposentar. Na carta, ele comenta ainda sobre uma associação clara entre os professores Antonio Rocha Penteado, José Ribeiro de Araújo Filho e Pasquale Petrone, sendo este último orientador de futuros professores da USP, vários deles ligados à renovação crítica. Ainda em 1980, Santos tem seu pedido de contratação negado pela Universidade Nacional de Brasília (Silva, 2011, p.44).

As cartas também revelam importantes projetos editoriais de Santos, como Fernandes (2 jun. 1983) e Santos (21 maio 1983), que mostram o processo de negociação da coleção Grandes Cientistas Sociais, publicada pela Ática. Florestan Fernandes, coordenador da coleção, indaga quem se responsabilizaria pelo volume sobre Josué de Castro, e Santos responde dizendo que Lobato Corrêa comporia um volume sobre autores anglo-saxões (David Harvey, Carl O. Sauer, Peter Haggett, Halford Mackinder e Richard Chorley); Armando Corrêa da Silva ficaria incumbido de Jean Tricart, Jean Brunhes e Camille Vallaux; Manuel Correia trataria de Josué de Castro ou talvez Camille Vallaux; e, por fim, Maria do Carmo Galvão seria responsável por um volume sobre a geografia alemã. Como sabemos, a coleção englobou efetivamente livros sobre Max Sorre, organizado por Januário Francisco Megale (em 1984); Élisée Reclus, por Manuel Correia (em 1985); e Friedrich Ratzel, por Antonio C.R. de Moraes (1990). Por fim, no início da década de 1980, Santos se corresponde com Pierre George (28 out. 1985), Michel Rochefort (22 out. 1985) e Bernard Kayser. Pudemos notar que, no seu retorno ao Brasil, Santos percebe que a corrente crítica ganhava fôlego na academia e na AGB, concomitantemente ao contexto de distensão da ditadura militar. Nesse sentido, nosso autor se prepara para a propagação da geografia crítica no Brasil, publicando livros de sua autoria que contêm concepções marxistas, defendendo uma geografia nova, nessa perspectiva, e aspirando traduzir e divulgar textos de colegas dos EUA. Assim, apesar de existir uma dificuldade inicial de se inserir em alguma universidade no Brasil, o exílio marcou de fato uma revolução simbólica, uma vez que o capital cultural acumulado no exterior lhe conferiu o reconhecimento das novas e antigas gerações de geógrafos. Dessa forma, o exílio foi um divisor de águas em sua trajetória, pois proporcionou o contato com figuras e debates pioneiros na experimentação de renovação da geografia nos EUA e na França.

Buscamos evidenciar que Santos, além de geógrafo profícuo, teve um papel protagonista como editor e articulador de redes científicas, interligando Brasil, América Latina, França e EUA. Essa articulação passou pela indicação de alunos para estudar no exterior, pela organização de números especiais em revistas prestigiadas e por sua presença na OIT. Pode-se falar aqui de um debate transnacional na medida em que Milton levou questões 
para serem debatidas no centro do sistema, sintetizadas no Espaço dividido (1975) com a proposta de uma teoria para compreensão da economia urbana no Terceiro Mundo. Ainda no exílio notamos sua preocupação em divulgar debates e concepção entre os colegas latinoamericanos. Paralelamente, ao voltar para o Brasil, Milton traz o debate do althusserianismo e outras ideias no sentido de se contrapor à geografia quantitativa e fortalecer a geografia crítica. Santos não foi, contudo, um reprodutor de ideias do estrangeiro, pois a sua proposta do conceito de formação socioespacial é original, sendo debatida no Brasil e nos EUA. Cabe lembrar que Richard Peet, Neil Smith e Yves Lacoste foram figuras centrais da geografia crítica e conquistaram reconhecimento mundial.

Intencionamos demonstrar que os contextos, os espaços e círculos sociais de produção da geografia de Milton Santos tiveram um importante peso na sua trajetória, mesmo que algumas perspectivas, como as concepções de planejamento de Perroux ou mesmo o althusserianismo, fossem gradativamente abandonadas e criticadas ao longo de sua carreira.

Ressaltamos ainda que, mesmo Santos estando no Brasil, seu prestígio no exterior persiste, o que é comprovado pela grande quantidade de títulos de doutor honoris causa recebidos desde 1980 até 1999 (15 no total, sendo cinco no exterior). Certamente, sua rede de trocas intelectuais tem vida longa após o exílio. Destacamos ainda sua preocupação em consolidar uma cultura geográfica com o projeto de publicar textos de autores clássicos da geografia, com apoio de Florestan Fernandes. A análise das cartas e a revisão da trajetória de Santos revela aspectos de sua relação com o marxismo, a formação da rede de contatos e suas estratégias acadêmicas no período de exílio.

\section{AGRADECIMENTO}

Trabalho realizado com apoio do Conselho Nacional de Desenvolvimento Científico e Tecnológico (CNPq).

\section{NOTAS}

${ }^{1}$ Para o número completo em homenagem a Santos, ver Scripta Nova (2002).

${ }^{2}$ Destacamos ainda em Antipode Foundation (15 mar. 2017) alguns artigos considerando a obra de Santos, republicando e revisitando "O papel ativo da geografia: um manifesto", publicado em 2000, um panfleto assinado por Milton conjuntamente com outros pesquisadores defendendo uma orientação para a práxis do campo da geografia.

${ }^{3}$ Como ressaltam Silva e Silva (2004), essa ideia surge nos primeiros escritos na Bahia e é retomada na maturidade.

${ }^{4}$ Silva e Silva (2004), contudo, destacam o contato prévio de Milton com os geógrafos franceses, ainda em 1954, quando era docente da Universidade Católica da Bahia.

${ }^{5}$ Vale ressaltar que na época John Friedmann, um dos formadores do planejamento regional, estava na Bahia, em função de uma cooperação técnica entre Brasil e EUA, ministrando cursos. Segundo informação por e-mail do professor Friedmann, Nailton Santos, irmão de Milton, foi seu aluno.

${ }^{6}$ Boudeville foi discípulo de François Perroux e deu uma conotação geográfica para suas ideias de espaço econômico e espaço geográfico. Basicamente, seu enfoque adaptava os dois conceitos e defendia o uso de três elementos básicos: (1) região polarizada, ou seja, aquela em que seus fluxos econômicos gravitam e são atraídos para um ponto, geralmente uma cidade; (2) região homogênea, uma região com pouca diferenciação econômica ou regionalizada a partir de poucas variáveis; e (3) região-plano, ou seja, recorte espacial integrado a um plano. Rochefort utiliza a proposta de Boudeville e toma como importante indicador de polarização dos espaços a presença do setor terciário, ou seja, o comércio e os serviços. Tais concepções são os predecessores do estudo Regiões de influência das cidades, 2007 (IBGE, 2008). 
${ }^{7}$ Araújo era ligado a Aroldo de Azevedo, que foi seguidor dos ensinamentos de Pierre Monbeig na USP.

${ }^{8}$ Uma consulta simples ao portal Persée indica 46 contribuições entre 1959 e 1992 em todas as revistas digitalizadas abrigadas pela plataforma; se considerarmos apenas a revista Tiers monde, são 23 publicações entre 1967 e 1988. Ver Persée (s.d.).

${ }^{9}$ Simplificadamente, vamos admitir que se trate da geografia crítica de origem estadunidense, calcada principalmente no marxismo. Sobre a problemática, consulte Pedrosa (2013, p.1-30).

${ }^{10}$ No original, "Spatial aspects of dependency: a prolegomenon to total planning".

${ }^{11}$ No original, "Perspectives on national growth and regional development in Nigeria, 1960-70".

12 Publicado pela Editora Methuen, que editou importantes obras da nova geografia, como a organizada por Peter Haggett, em 1967, Models in geography.

${ }^{13}$ Artigo republicado na edição que busca recontar a consolidação da geografia crítica (Santos, 1985).

${ }^{14}$ Provavelmente, trata-se do texto "Inequality and poverty: a Marxist-geographic theory" (Peet, 1975).

${ }^{15}$ No original, "The poverty of modern geographical enquiry".

${ }^{16}$ No original, "It is to introduce a new drive in our discipline which is knowing now a kind of renovation".

${ }^{17}$ No original, "Uneven development and environment".

${ }^{18}$ A geografia quantitativa ou teorética foi uma corrente que defendeu o ponto de vista nomotético, a neutralidade científica, o uso de modelos e da linguagem matemática para a compreensão dos fenômenos geográficos e uma concepção de espaço baseada nos moldes cartesianos. Ela foi frontalmente atacada pela geografia crítica de cunho marxista; contudo, alguns quantitativos abandonaram a corrente para se tornar críticos. O caso mais célebre é o de David Harvey. No Brasil, o IBGE foi um dos lócus da geografia quantitativa.

${ }^{19}$ No original, "Concepts: development, environment, location".

\section{REFERÊNCIAS}

AKIWOWO, Akinsola.

Carta a Milton Santos. Acervo Milton Santos, MS-RS76-008 (Instituto de Estudos Brasileiros, São Paulo). 27 set. 1976.

\section{ANTIPODE FOUNDATION.}

Symposium: Introducing Milton Santos and "The active role of geography". Disponível em: https:// antipodefoundation.org/2017/03/15/introducingmilton-santos-and-the-active-role-of-geography/. Acesso em: 6 ago. 2017. 15 mar. 2017.

AB'SÁBER, Aziz.

Carta a Milton Santos. Acervo Milton Santos, MS-RS80-008 (Instituto de Estudos Brasileiros, São Paulo). 30 mar. 1980.

BEAUJEU-GARNIER, Jacqueline.

Carta a Milton Santos. Acervo Milton Santos, MS-RS76-008 (Instituto de Estudos Brasileiros, São Paulo). 9 jan. 1978.

BOMFIM, Paulo Roberto de Albuquerque; VARGAS, Héctor Mendonza.

La geografía latinoamericana y la Unión Geográfica Internacional (UGI): los casos de Brasil (1956) y México (1966). Journal of Latin American Geography, v.13, n.1, p.215-232. 2014.

BRITO, Thiago Macedo Alves de.

A metamorfose do conceito de região: leituras de Milton Santos. Geographia, v.10, n.20, p.74-105. 2008.
BUSS, Maria Dolores et al.

Entrevista com o professor Milton Santos. Geosul, v.6, n.12, p.116-147. 1991.

CENTRE..

Centre d'Études de Géographie Tropicale. $L a$ régionalisation de l'espace au Brésil. Paris: Éditions du CNRS. 1971.

CONTEL, Fábio Betioli.

Milton Santos. In: Secco, Lincolm; Pericás, Luiz Bernardo. Intérpretes do Brasil. São Paulo: Boitempo. p.393-409. 2014.

CORRÊA, Roberto Lobato.

Carta a Milton Santos. Acervo Milton Santos, MS-RS78-041 (Instituto de Estudos Brasileiros, São Paulo). 3 mar. 1978.

CUSSET, François.

French theory. Paris: La Découverte. 2005.

FERNANDES, Florestan.

Carta a Milton Santos. Acervo Milton Santos, MS-RS83-042 (Instituto de Estudos Brasileiros, São Paulo). 2 jun. 1983.

GEORGE, Pierre.

Carta a Milton Santos. Acervo Milton Santos, MS-RS85-028-A e B (Instituto de Estudos Brasileiros, São Paulo). 28 out. 1985. 
GEORGE, Pierre.

Conferências no Brasil. Rio de Janeiro: Fundação IBGE. 1970.

GRIMM, Flávia C.A.

Aspectos da produção teórica e da organização do arquivo de documentos do geógrafo Milton Santos. Revista do IEB, n.52, p.165-182. 2011a.

GRIMM, Flávia C.A.

Trajetória epistemológica de Milton Santos: uma leitura a partir da centralidade da técnica, dos diálogos com a economia política e da cidadania como práxis. Tese (Doutorado em Geografia Humana) - Faculdade de Filosofia, Letras e Ciências Humanas, Universidade de São Paulo, São Paulo. 2011b.

IBGE.

Instituto Brasileiro de Geografia e Estatística. Regiões de influência das cidades, 2007. Rio de Janeiro: IBGE. 2008.

JEANPIERRE, Laurent.

Une opposition structurante pour

l'anthropologie structurale: Lévi-Strauss contre Gurvitch, la guerre de deux exilés aux ÉtatsUnis. Revue d'Histoire des Sciences Humaines, v.11, n.2, p.13-44. 2004.

LINDENBOIM, Javier.

Carta a Milton Santos. Acervo Milton Santos, MS-RS76-018 (Instituto de Estudos Brasileiros, São Paulo). 16 jul. 1976.

MACHADO, Mônica Sampaio.

Milton Santos. In: Machado, Mônica Sampaio; Martin, André Roberto. Dicionário dos geógrafos brasileiros. v.1. Rio de Janeiro: 7 Letras. p.133166. 2014.

MAMIGONIAN, Armen.

Milton Santos: a formação de um pensador universitário crítico. In: Brandão, Maria A. (Org.). Milton Santos e o Brasil. São Paulo: Editora Fundação Perseu Abramo. 2004.

MELGAÇO, Lucas; PROUSE, Carolyn. Milton Santos: a pioneer in critical geography from the global south. London: Springer. 2017.

MITCHELL, Don.

Neil Smith, 1954-2012: marxist geographer. Annals of the Association of American Geographers, v.104, n.1, p.215-222. 2014.

MORAIS, Antonio Carlos R. de.

Território na geografia de Milton Santos. São Paulo: Annablume. 2013.

MULCHANSINGH, Vernon Chandra. Carta a Milton Santos. Acervo Milton Santos, MS-RS76-009 (Instituto de Estudos Brasileiros, São Paulo). 11 jun. 1976.
NOGUEIRA, Amélia Alba.

Ciclo de conferências geográficas no Conselho Nacional de Geografia. Revista Geográfica, t.19, n. 45, p.210-213. 1956.

PEDROSA, Breno Viotto.

Entre as ruínas do muro: a história da geografia crítica sob a ótica da ideia de estrutura.

Tese (Doutorado em Geografia Humana) Universidade de São Paulo, São Paulo. 2013.

PEET, Richard.

Carta a Milton Santos. Acervo Milton Santos, MS-RS83-022 (Instituto de Estudos Brasileiros, São Paulo). 3 fev. 1983.

PEET, Richard.

Carta a Milton Santos. Acervo Milton Santos, MS-RS77-014 (Instituto de Estudos Brasileiros, São Paulo). dez. 1977.

PEET, Richard.

Carta a Milton Santos. Acervo Milton Santos, MS-RS77-014 (Instituto de Estudos Brasileiros, São Paulo). out. 1977.

PEET, Richard.

The development of radical geography in the United States. Progress in Human Geography, v.1, n.2, p.240-263. 1977.

PEET, Richard.

Inequality and poverty: a Marxist-geographic theory. Annals of the Association of American Geographers, v.65, n.4, p.564-571. 1975.

PERSÉE.

Persée: portail de revues scientifiques en sciences humaines et sociales. Santos, Milton (19262001). Disponível em: http://www.persee.fr/ authority/266884. Acesso em: 16 out. 2016. s.d.

ROCHEFORT, Michel.

Carta a Milton Santos. Acervo Milton Santos, MS-RS85-099 (Instituto de Estudos Brasileiros, São Paulo). 22 out. 1985.

SANTOS, Milton.

Spatial dialectics: the two circuits of urban economy in underdevelopment countries. Antipode, v.17, n.2-3, p.127-135. 1985.

SANTOS, Milton.

Carta a Florestan Fernandes. Acervo Milton Santos, MS-RS83-042 (Instituto de Estudos Brasileiros, São Paulo). 21 maio 1983.

SANTOS, Milton.

Carta a Richard Peet. Acervo Milton Santos, MSRS77-014 (Instituto de Estudos Brasileiros, São Paulo). 3 fev. 1983.

SANTOS, Milton.

Carta a Yves Lacoste. Acervo Milton Santos, MSRS80-014 (Instituto de Estudos Brasileiros, São Paulo). 29 fev. 1980. 
SANTOS, Milton.

Carta a David Slater. Acervo Milton Santos, MSRS78-029 (Instituto de Estudos Brasileiros, São Paulo). 6 mar. 1978.

SANTOS, Milton.

Carta a Richard Peet. Acervo Milton Santos, MSRS77-014 (Instituto de Estudos Brasileiros, São Paulo). fev. 1978.

SANTOS, Milton.

Rêve et cauchemar: problèmes spatiaux de la transition au socialisme: le cas de la Tanzanie. Tiers Monde, v.19, n.75, p.563-572. 1978.

SANTOS, Milton.

Carta a Richard Peet. Acervo Milton Santos, MSRS77-014 (Instituto de Estudos Brasileiros, São Paulo). mar. 1977.

SANTOS, Milton.

Society and space: social formation as theory and method. Antipode, v.9, n.1, p.3-13. 1977.

SANTOS, Milton.

L'alimentation des populations urbaines de pays sous-développés. Tiers Monde, v.8, n.31, p.605629. 1967.

\section{SANTOS, Milton.}

Les difficultés de développement d'une partie de la zone sèche de l'État de Bahia: vallée moyenne du fleuve Paraguaçu. Annales de Géographie, v.72, n.391, p.314-330. 1963.

SANTOS, Milton.

Quelques problèmes des grandes villes dans le pays sous-dévelopés. Revue de Géographie de Lyon, v.36, n.3, p.197-218. 1961.

SANTOS, Milton.

Quelques problèmes géographique du centre de la ville de Salvador. L'Information Géographique, v.23, n.3, p.93-98. 1959.

SANTOS, Milton.

Zonas de influência comercial do Estado da Bahia: interpretação a um inquérito sobre comércio e abastecimento no Estado da Bahia. Diretório Regional de Geografia, n.2, p.1-17. 1956a.

SANTOS, Milton.

O papel metropolitano da cidade do Salvador. Salvador: Gráfica Americana. 1956b.

SANTOS, Milton.

Problemas de geografia urbana na zona cacaueira baiana. Comunicação apresentada no 18. Congresso Internacional de Geografia, 1956. Rio de Janeiro. 1956c.
SANTOS, Milton; CARVALHO, Ana.

A geografia aplicada. Boletim Geográfico, n.185, p.249-258. 1965.

SANTOS, Milton; CARVALHO, Ana. A geografia aplicada. Salvador: Imprensa Oficial da Bahia. 1960.

SANTOS, Milton et al.

Estudos de geografia da Bahia. Salvador:

Publicações da Universidade da Bahia. 1958.

SCRIPTA..

Scripta Nova, v.6, n.124 (El ciudadano, la

globalización y la geografía:

homenaje a Milton Santos), 30 set. 2002.

Disponível em: http://www.ub.edu/geocrit/sn/ sn-124.htm Acesso em: 15 fev. 2018. 2002.

SILVA, Maria Auxiliadora.

10 anos sem Milton Santos. Salvador: Alba. 2011.

SILVA, Maria Auxiliadora.

Milton Santos: a trajetória de um mestre. Scripta Nova, v.6, n.124, p.1-11. 2002.

SILVA, Maria Auxiliadora; SILVA, Fábio Santos.

Uma leitura de Milton Santos (1948-1964).

Geosul, v.19, n.37, p.157-189. 2004.

SMITH, Neil.

Gentrification and capital: practice and ideology in Society Hill. Antipode, v.11, n.3, p.24-35. 1979.

SMITH, Neil.

Carta a Milton Santos. Acervo Milton Santos, MS-RS78-055 (Instituto de Estudos Brasileiros, São Paulo). 7 set. 1978 .

SMITH, Neil.

Carta a Milton Santos. Acervo Milton Santos,

MS-RS78-054 (Instituto de Estudos Brasileiros, São Paulo). 21 jun. 1978.

SMITH, Neil.

Carta a Milton Santos. Acervo Milton Santos, MS-RS78-056 (Instituto de Estudos Brasileiros, São Paulo). fev. 1978.

SMITH, Neil.

Carta a Milton Santos. Acervo Milton Santos, MS-RS78-056 (Instituto de Estudos Brasileiros, São Paulo). jun. 1976.

SOUZA, Maria Adélia Aparecida de.

O mundo do cidadão, um cidadão do mundo. São Paulo: Hucitec. 1996.

UYANGA, Joseph Theophilus.

Carta a Milton Santos e Richard Peet. Acervo

Milton Santos, MS-RS76-007 (Instituto de

Estudos Brasileiros), São Paulo. dez. 1976. 